Acta Hispanica (2018) 23: 273-285

\title{
CHOCOLATE, CACAO, AGUACATE... ALIMENTOS SIN FRONTERAS
}

\author{
NóRA RóZSAVÁRI
}

Universidad Católica Pázmány Péter

\begin{abstract}
Resumen: Debido al descubrimiento de América, varios alimentos americanos llegaron a la Península Ibérica y a Europa. Los españoles tuvieron que nombrar los nuevos productos, o comparándolos con los ya conocidos o dándoles denominaciones prestadas de las lenguas amerindias. En este artículo se analizan tres palabras de origen amerindio: chocolate, cacao y aguacate. Se explica cómo llegaron al húngaro, se da la fecha y la fuente de las primeras documentaciones, se informa de los cambios formales, semánticos y referenciales, y también se presenta el proceso de integración en el húngaro.
\end{abstract}

Palabras clave: alimentos, lenguas amerindias, mediación española

Abstract: Due to the discovery of America, several American foods arrived in the Iberian Peninsula and Europe. The Spaniards had to name the new products comparing them with those already known or by giving them denominations borrowed from the Amerindian languages. In this article three words of Amerindian origin are analyzed: chocolate, cocoa and avocado. The article explains how they came to Hungarian, the date and source of their first documentation is given, formal, semantic and referential changes are reported, and their integration in Hungarian is also presented.

Keywords: food, Amerindian languages, mediation of Spanish

\section{La llegada de voces amerindias a Europa}

En 1492 la expedición que culminó con el descubrimiento de América, llegó a ser uno de los viajes más importantes de la historia. Se abrieron nuevos horizontes: el tamaño de la tierra habitada se duplicó y el contacto entre las culturas tuvo un enorme impacto e importantes consecuencias tanto en América como en Europa. Debido al encuentro de los dos mundos, se intoducían nuevas especies vegetales, animales y productos naturales en ambos continentes. Los europeos fueron aportando el trigo, la vid, las vacas y las ovejas, mientras traían productos antes nunca vistos ni conocidos como, por ejemplo, el tomate, el maíz o la patata. Los nuevos alimentos poco a poco llegaron a ser conocidos e intoducidos como ingredientes en la cocina del Viejo Mundo. 
Los navegantes, expedicionistas y conquistadores se enfrentaron con una nueva flora y fauna en América. Para nombrar lo desconocido recurrían a la comparación con algo ya conocido utilizando una palabra patrimonial con un contenido ampliado (aligátor < el lagarto), otras veces crearon nuevas formas hispánicas mediante derivación o composición (vaina $>$ vainilla), sin embargo, muchas veces optaron por utilizar palabras amerindias que fueron adaptándose fónica y morfológicamente en el español (tómatl > tomate).

Fue la lengua española en la que primero se prestaron las palabras indígenas y la que transmitió varias denominaciones de alimentos a las lenguas europeas. La Monarquía Hispánica, consolidada por Carlos I en el siglo XVI, comprendía grandes extensiones de territorios europeos (alcanzó su máxima expansión entre los años 1580 y 1640), hecho que hizo posible la propagación de los productos amerindios y sus denominaciones casi en toda Europa (Países Bajos, reinos de Nápoles y Sicilia, Milanesado, Borgoña, Austria, etc.).

El español nunca ha tenido contacto directo con el húngaro, pero gracias a la mediación del francés y, sobre todo, del alemán, en nuestra lengua también encontramos varias palabras adoptadas del castellano que, por su parte, tienen su origen en lenguas amerindias. Aunque las palabras estudiadas en este ensayo lingüísticamente son consideradas préstamos del alemán o del francés (germanismos y galicismos, respectivamente), al fin y al cabo, cuando nos interesamos por el origen, herencia o contacto cultural, hay que resaltar que estos vocablos se remon$\tan$ a un origen amerindio.

La influencia alemana sobre la lengua húngara ha sido contundente. El contacto húngaro-alemán se remonta al siglo IX, se fortalece desde el siglo XVI, cuando la dinastía de los Habsburgo extiende su poder a algunos territorios húngaros, y llega a la culminación cuando dicha dinastía obtiene la Corona Húngara. Desde finales del siglo XVII el contacto lingǘstico húngaro-alemán se ve consolidado por el establecimiento de población de lengua materna alemana en regiones de Hungría. Asimismo, desde el siglo XVIII Viena transmitió numerosas novedades e innovaciones a las lenguas de la monarquía austrohúngara; por lo tanto, varias palabras procedentes del italiano, del francés o de otras lenguas se introdujeron en el húngaro con sus formas alemanas. 
Diversos nombres de alimentos que son comunes a varias lenguas europeas (patata, tomate, maíz, etc., y sus formas adaptadas a las lenguas receptoras) sobreviven en el húngaro con sus denominaciones de origen alemán, latino o eslavo. Existen, sin embargo, tres vocablos que sí penetraron en el húngaro: csokoládé 'chocolate', kakaaó ‘cacao' y avokádó 'aguacate'.

\section{Denominación de algunos alimentos americanos en el húngaro ${ }^{1}$}

\subsection{Csokoládé}

La palabra csokoládé llegó al húngaro por la mediación del alemán (al. Schokolade) con el significado 'bebida de cacao'. Más tarde se generalizó el significado que se refiere a las tabletas y pastillas en las que se expende.

Al principio nació toda una familia de palabras con formas bastante diversas como se podrá ver más adelante.

La primera documentación de la palabra se data en 1699 (Benkő, 1993:223) con la forma flexionada csukorlatéhoz, cuya raíz es csukorlate. El vocablo aparece en un facsímil del archivo de una familia noble: "Csukorlatéhoz végy, más konyhára valo torma reßelőert", que quiere significar: 'Para rallar el chocolate, coge un rallador que sueles utilizar en la cocina'.

Al mismo tiempo el Diccionario Histórico Etimológico de la Lengua Húngara (A magyar nyelv történeti-etimológiai szótára; TES ₹) fecha la aparición en 1704 con la forma csukaladi (TES₹. I:549): "Csukaladi és herbaté Bornál jobb volna": 'Chocolate y tisana serían mejores que el vino'.

Desde estas fechas en adelante la palabra aparece en distintos años con distintas formas, y aunque se documentan variantes, poco a poco el término csokoládé llega a generalizarse. Debido al carácter aglutinante de la lengua húngara, el sustantivo a veces aparece con sufijos, que en la lista se separan con un guión. A continuación

\footnotetext{
${ }^{1}$ Este apartado es una versión abreviada del artículo de la autora "Chocolate, cacao y aguacate en húngaro" Erlendsdóttir, Erla-Martinell - Emma-Söhrman, Ingmar (eds.) 2017. De América a Europa. Denominaciones de alimentos americanos en lenguas europeas. Madrid: Iberoamericana-Vervuert. 359-373.
} 
se relacionan algunas variantes del vocablo con la fechas de su primera documentación.

1706 csokuládi-val 'con chocolate'; 1736 csukolátá-nak 'de chocolate'. En 1949 en la revista de cultura del idioma Magyar Nyelvốr ( $\mathrm{Nyr}$ ) se publicó un artículo que estudiaba los préstamos italianos del húngaro (Nyr 73:19). El apartado que trata del chocolate menciona que csokoládé es un préstamo del alemán, pero destaca que, al mismo tiempo, en el húngaro existe una variante csokoláta, equivalente de csokoládé, que es un italianismo. La documentación de la forma alemana es anterior (1706), mientras la forma italiana aparece unas décadas más tarde (1736): "Az beteges feleségem alázatossan udvarol Nagyságodnak csokuládival”, es decir: 'Mi esposa malsana le corteja a su señoría con chocolate' (Nyr 73:19). "Legelsőben is reggeli kávé, herbathé, csukolátának hire sem vala", 'En aquellos tiempos de café, té de hierbas y de chocolate no hubo ni rastro' (Nyr 73:19), escribe Péter Apor historiador, en su obra Metamorphosis Transylvaniae, que habla de las transformaciones que tuvieron lugar en la vida cotidiana de Transilvania en el siglo XVIII.

1748 cioccolátá-val 'con chocolate'. El escritor, poeta y traductor jesuita Ferenc Faludi utiliza una ortografía italiana cuando escribe en una de sus obras: "Eusebius bőcsúletesen fogadta, annak rendi szerint kinálta egy csésze cioccolatával, de a damak mentegeték vala magokat", 'Eusebio las recibió honradamente, les ofreció chocolate, pero las damas se excusaron' (Szarvas et al. 1890:446).

1774 csukuláté; 1799 tsukoládé. La Revista de la Asociación Húngara de Lingüistas, Magyar Nyelv (MNy), en una serie de artículos que enumera datos etimológicos, publicó en 1942 los resultados de una investigación centrada en los archivos familiares del Museo de Transilvania. Los datos que se recogieron principalmente del material relacionado con los bienes y posesiones de la familia del barón Wesselényi citan la palabra en cuestión: "két kopott aranyozással valo [...] Csukuláté finssía tartó”, 'dos tazas usadas chapadas de oro [...] para guardar chocolate'. "Tizenöt Font Tsukoládé”, 'Quince libras de chocolate' (MNy 38:56).

1816 tsokoláde. El lingüista y médico Sámuel Gyarmathi en su diccionario Vocabularium in quo plurima bungaricis vocibus consona variarum linguarum vocabula collegit... relaciona la palabra con la forma tsokoláde (TESそ I:549). 
El Diccionario Histórico Etimológico de la Lengua Húngara hace mención de algunas formas dialectales o provinciales, como por ejemplo: cukoládé, csúgladé, csukaládé, kocsoládé (TES z I:549). La forma actual csokoládé desde el siglo XIX parece tener más constancia que sus variantes. Abundamos en textos de la época que utilizan esta forma:

El escritor Mihály Táncsics en su novela Pazardi publicada en 1836, describe la vida disipada y pródiga de los magnates húngaros y cuando pasa revista a los gastos escribe: “Az élelem szükségek, kávé, nádméz, csokoládé, fűszer, só, szóval, mit a hasisten megkiván, külföldi borok sat. hat ezer", 'Las necesidades de alimentos, café, miel de caña, chocolate, condimentos, sal, o sea lo que el dios de la panza desea, vinos extranjeros, etc., seis mil' (1836:23).

En 1845 el sacerdote, profesor y zoólogo János Hanák escribió una historia de la naturaleza en la cual describía, varias plantas. Hablando de la vainilla dice que sirve para dar sabor al chocolate: "ezen hüvely megszarítva a hevítő erejéről nevezetes vanilia, melly mint füszer a csokoládé alkatrészér teszi”, que quiere decir: 'esta vaina seca, famosa por sus efectos excitantes, es la vainilla, que es un componente del chocolate' (1845:140).

El escritor y poeta húngaro Péter Tatár en su obra $A$ megholt peleskei nótárius. Nagy Zajtay István másodszori feltámadása és utazása a földön de 1860 cuenta las aventuras de un notario provinciano. En su poema pregunta: "Director Uram hát van e csokoládé”, es decir: 'Señor Director, chay chocolate?' (1860:64).

El punto de partida, según Corominas, sería el español *chocanatl (2011:197) que tuvo diversas adaptaciones en las lenguas receptoras. En el Diccionario Histórico Etimológico de la Lengua Húngara figura como étimo la voz nahuatl chocolaia que durante el dominio español supuestamente tomó la forma chocolatl (TES ₹ I:549). Respecto a la evolución de las formas húngaras hay que tener en cuenta la mediación alemana, por ejemplo, la -d- de csokoládé se debe al alemán Schokolade, pero las diversas formas húngaras posiblemente son resultados de múltiples préstamos. Cabe señalar que también en el alemán coexistieron distintas variantes, por lo que se le atribuyen al alemán las vocales finales húngaras é e $i$, o la falta de la vocal final. Suponen préstamo del italiano las formas con $-k k-\mathrm{y}$ las que llevan una $-a$ final, aunque respecto a estas últimas pudo tener un papel influyente la latinidad nacional (el latín era lengua oficial de Hungría hasta 1844). La - a final no necesariamente se debe a la influencia 
italiana, algunos lingüistas opinan que este fenómeno también puede remitir a una forma antigua alemana schokolata (TESそ I:549). La vocal $u$ que muchas veces aparece en la primera o segunda sílaba también puede tener antecedentes en el alemán hablado en Hungría. Las distintas vías de préstamo, las combinaciones, mezclas y algunas evoluciones fonéticas en el húngaro dieron como resultado la forma actual húngara csokoládé.

\subsubsection{Csoki}

Géza Bárczi, lingüista húngaro, en su artículo A “pesti nyelv" publicado en 1932 menciona por primera vez la forma abreviada csoki ( $M N y$ 28:90). En el ensayo se llama la atención sobre un fenómeno en propagación de la época: la deformación de palabras a través de sufijos. De estos sufijos el más utilizado ha sido -i, que, fortalecido por el diminutivo de la misma forma (-i), frecuente en el argot alemán originó numerosas formas nuevas. El sufijo -i generalmente se ha agregado a la raíz truncada, lo que en nuestro caso ha dado la forma csoki, una demoninación con diminutivo afectivo. El sufijo en cuestión hasta hoy es un sufijo muy productivo en el húngaro en la formación de palabras. Esta forma abreviada ampliamente utilizada ha ido incorporando varias acepciones en la jerga. Hoy, en el registro jergal significa 'persona de piel negra u oscura; negro, gitano' (Kövecses, 1998:57) Una de las primeras documentaciones de este uso la encontramos en la novela Szökeöár (1954) del escritor húngaro Miklós Vidor, quien escribe de la vida de unos jóvenes budapestinos en los años posteriores a la Segunda Guerra Mundial. Uno de los protagonistas se llama Csoki (1954:331).

La forma abreviada se aplica con preferencia en la jerga y también ha llegado a formar parte de palabras compuestas. Existe el vocablo húngaro romacsoki, literalmente 'chocolate gitano' cuyos componentes son roma 'gitano' y csoki 'chocolate', y significa 'pipas', haciendo alusión a la costumbre de la minoría gitana de comer semillas de girasol. En la jerga juvenil actual csokirik (verbo derivado de csoki) 'comer chocolate' se utiliza con el significado de 'hacer chocolate' y equivale a 'hacer caca' (napiszleng.hu 15-01-2018).

La propagación y generalización del sustantivo húngaro csokoládé / csoki está en estrecha relación con el consumo pasado y actual del producto. Los primeros talleres fabricantes de chocolate en Hungría aparecieron en el siglo XVIII debido a la llegada de artesanos italianos. Aparte de ellos solo los farmacéuticos y botica- 
rios producían y vendían chocolate. Con el paso del tiempo los efectos curativos del chocolate se relegaron a segundo plano, y los consumidores lo compraban por su valor nutritivo y sabor. A mediados del siglo XIX se fundaron varias fábricas, y a fines del siglo ya funcionaban unas 60 plantas industriales, sin embargo, por el elevado precio, el consumo se restringió solo a los círculos aristocráticos. Después de la I Guerra Mundial el chocolate, que antes era un producto de lujo, pasó a ser un artículo de primera necesidad y de amplio consumo.

\subsection{Kakaó}

Se trata de un préstamo que llegó al húngaro vía el alemán (al. Kakao), primero con el significado de semillas de cacao y el polvo obtenido al triturarlas, luego con el significado de bebida que se prepara a partir de ese polvo. La primera documentación de la palabra data de 1757. Pál Bertlanffi, profesor y escritor jesuita, la menciona en su obra Világnak, két rendbéli rörid ismerete: "bővelkedik csokoladára való Cacao névú makkal”: 'abunda en bellotas llamadas Cacao que sirven para hacer chocolate' (TES₹ II:310). La primera aparición, todavía con ortografía extranjera, la siguen las versiones hungarizadas: 1780 kakáo-vajból 'de manteca de cacao’ (TES そ II:310).

1783 Kákáa-fa 'árbol de cacao'. János Molnár, profesor y escritor jesuita, fundador de la Revista Magyar Könyvesház menciona el vocablo (TES z II:310). La revista tenía fines divulgadores. Molnár escribió reseñas, presentó los resultados de investigaciones científicas y publicó informes científicos como autor, director y redactor de la revista.

1787 Kákáó-bab-nak 'a la semilla de cacaco’. József Gelei tradujo al húngaro la novela Robinson der Jüngere del escritor, lingüista y educador alemán Joachim Heinrich Campe. En esta novela se nombra la semilla de la planta (1787:223).

1789 kakau-t 'a cacao'. Raphael Steidele, cirujano austriaco, escribió varias obras para mujeres embarazadas y recién paridas, una de ellas traducida al húngaro por Mihály Gellei (Regulák)) trae este vocablo (TESそ II:311).

Las palabras kakajó, kakavó se registran como dialectalismos, en ellas se ve la tendencia antihiática con la intercalación de una consonante (TES z II:311). 
La propagación del producto fue acompañada por la propagación lingüística. El término kakaó se ha convertido en elemento común de libros de cocina, de periódicos y revistas, y de cuentos y novelas:

1933 En la revista judía Zsidó Újság, en la publicidad de algunas tiendas, encontramos listas de productos: "csokoládé, kakaó, lekvár. paradicsom, bor" 'chocolate, cacao, mermelada, tomate, vino’ (Zsidó Újság 1933:11).

1956 Kakaó es el título de un cuento del escritor húngaro Ferenc Sánta, que escribe sobre una reunión de niños: "Ott ültek a nagy asztal körül, s ettek. Vajat, mézet, sonkát, és végigáradt az udvaron, még az utcára is kilibbent a kakaó illata" que quiere decir: "Allí estaban sentados, alrededor de la mesa grande y estaban comiendo. Mantequilla, miel, jamón, y en el patio hasta la calle emanaba el olor del cacao.'

1959 En el cuento A nyeremény de Imre Sarkadi la bebida del cacao simboliza la vida lujosa de la que disfruta una familia después de haberle tocado un premio: "A felesége bejárónőt fogadott, minden reggel vaj volt, kakaó, vagy tejszínhab", es decir: 'su esposa contrató a una sirvienta, todas las mañanas había mantequilla, cacao o nata montada.'

Según el Diccionario Histórico Etimológico de la Lengua Húngara, la raíz del vocablo es la voz náhuatl kakáwatl/kakáwa (TESz II:311) y fue transmitida a las lenguas europeas por mediación del idioma español. La forma actual húngara obedece a las reglas gramaticales y ortográficas de nuestro idioma, ya que en el húngaro la vocal -ó en posición final siempre es larga, lo que se indica con una tilde.

Kakaó también forma parte del registro jergal. Es sinónimo de fuerza, volumen, o energía. Ejemplos:

Van benne kakaó 'tiene/lleva cacao' lo cual quiere decir que tiene fuerza; Adj rá kakaót 'da(le) cacao' es decir, da(le) más volumen a la música; o acelera, dale al pedal de acelerador'.

También se usa como eufemismo en vez de la palabra kaka 'caca' en expresiones como benne van/hagy a kakaóban lo cual quiere decir 'estar/dejar alguien en el cacao', o sea 'estar/quedarse en una situación difícil', o kibúr a kakaóból 'sacar alguien del cacao', es decir, 'sacar alguien de los problemas'. 
La historia del consumo del cacao recorre la misma trayectoria que la del chocolate, aunque según las estadísticas, mientras el consumo del chocolate va aumentando, el del cacao (en forma de polvo, bebida, etc.) ha experimentado una disminución considerable en los últimos años.

\subsection{Avokádó}

La mayoría de los nombres de frutas exóticas no aparece en los diccionarios etimológicos húngaros. La voz avokádó, conocida desde la segunda mitad del siglo XIX y hasta hoy, se registra también en el Diccionario de Palabras Extranjeras (Idegen szavak szótára), aunque en el uso ya suena familiar a los hablantes (Tolcsvai 2007:104). Según el Diccionario Etimológico de Palabras y Afijos Húngaros (Etimológiai szótár. Magyar szavak és toldalékok eredete) la palabra se generalizaría en el uso solo en los años 1970 (Zaicz 2006:46). Los diccionarios etimológicos anteriores no incluyen dicho vocablo, pero las enciclopedias, los distintos escritos y publicaciones de botánicos, de médicos, de gastrónomos, y también las crónicas de viajes sirven como fuentes para la documentación. La Enciclopedia Pallas (A Pallas nagy lexikona) tiene una entrada avogate-fa, avogató-fa 'árbol de aguacate' que parece ser la primera aparición escrita húngara, y se refiere a la planta en cuestión (Áldássy et. al., eds. 1894: vol. II:376). La misma enciclopedia muestra vacilación, ya que en ediciones y tomos posteriores (1896) se mencionan distintas formas: avogato, advokato, abakadó, que también aparecen en palabras compuestas, como avogatófa, avogatefa, avokatófa que se refieren al árbol (vol. XIII: 955).

1922 avocato, aguacate son las formas que recoge otra enciclopedia húngara, el Diccionario Enciclopédico Révai (vol. XV:350).

1983 avokadó. Los autores del libro Nálunk is megterem. Históriák és tanácsok egzotikus gyümölcs-és füszernövények neveléséhez describen el origen de 20 frutas exóticas, entre ellas el aguacate, y dan consejos para su cultivo en un estilo ameno y comprensible (Velich, 1983:95).

1985 avokádó. La obra de Dezső Surányi Kerti növények regénye es una novela sobre distintas plantas. Novela, ya que comprende elementos de la religión, del folclore, de la historia y de las ciencias naturales (1985:145). 
1986 avokádó(fa) '(árbol de) aguacate’. Szaniszló Priszter redactó un vocabulario húngaro-latín que informa sobre la ortografía correcta de los nombres de plantas exóticas (1986:34).

La composición con $-f a$, 'árbol', es frecuente al referirse a la planta. Después de una vacilación natural aguakata-fa, avogatófa, avogatefa, avocatófa, agáte-fa, se fijan las formas actuales de avokádó-fa, avokádó(fa). Las primeras variantes probablemente se deben a formas alemanas y son traducciones de: Abacatebaum, Advocato-baum, Advogatebaum, Advogatobaum, Aguacatebaum, Avocatobaum, Avogatenbaum, Avogatobaum.

Tanto las primeras enciclopedias como los libros técnicos hacen mención de la fruta, utilizando el término aligátorkörte compuesto de aligátor 'aligátor' y körte 'pera'. A continuación se relacionan las fechas y las formas: en 1896 se atestigua la forma alligator-körte (Pallas vol. XII:955); en 1922 alligátor-körte (Révai vol. XV:350) y la misma forma, alligátor-körte, se documenta también en 1983 (Velich 1983:95) y finalmente en 1987 aparece aligátor körte que es la forma adaptada a las reglas ortográficas húngaras.

Para referirse a la fruta también se han seguido modelos extranjeros. Las variantes húngaras con -körte 'pera', avogato-körte, advokato-körte, avocado-körte, avogado-körte, avokadókörte, avokádó körte, etc., se han tomado del alemán Avocatobirne, Avogadobirn y del inglés avocado pear, y son calcos parciales. Para el origen de la denominación surgen varias explicaciones, por un lado, el primer elemento puede referirse al color verde oscuro de la fruta o, tal vez, es una alusión al lugar de procedencia de la fruta, donde viven caimanes.

En la segunda mitad del siglo XX se generaliza la presencia de la palabra avokádó en el léxico húngaro. El motivo es que se multiplican las traducciones de trabajos científicos y gastronómicos alemanes e ingleses (Por ejemplo la traducción de Urania Pflanzenreich. Höhere Pflanzen en los años 1970 y la de DK Pocket Encyclopedia. Cook's Ingredients en 1991). Además en 1982-83 el Comité de Ortografía de la Academia Húngara de Ciencias y el Comité de Botánica de la Academia aceptaron un código de reglas para la escritura correcta de los nombres de las plantas y frutas recién entradas en el vocabulario húngaro. 
Como étimo de la palabra, en su tesis doctoral, Éva Vörös nombra la voz náhuatl abuacacuabuitl (1996:13) que por vía del inglés y del alemán ha llegado al húngaro y, después de una adaptación fonética y ortográfica, ha obtenido la forma avokádó (como en el caso de kakaó se puede observar la regla general del húngaro según la cual la -ó final es siempre larga.)

La voz avokádó no forma parte del registro jergal y tampoco aparece en frases hechas o refranes, posiblemente por el hecho de que es un producto relativamente nuevo en los mercados húngaros. Desde los años 2000 se generaliza su presencia en las tiendas y supermercados aunque su consumo es relativamente modesto si se compara con otras verduras y frutas más tradicionales.

\section{Notas finales}

Desde épocas antiguas, los alimentos viajan por todo el mundo, ignorando las fronteras. El té, el café, el tabaco, el arroz del Oriente fueron conocidos en Europa gracias a los pueblos comerciantes. El descubrimiento de América aportó varios productos occidentales a la alimentación europea. Muchos de estos productos viajaron con sus nombres, conservando en la denominación también su origen amerindio. Las voces amerindias primero se prestaron en el español donde pronto llegaron a formar parte sustancial del vocabulario. Del español pasaron a otras lenguas europeas, donde se asentaron en el léxico o fueron sustituidas por vocablos de otros orígenes. Este estudio ha pretendido mostrar la suerte de tres vocablos amerindios en el húngaro: chocolate, cacao y aguacate. Los nombres de estos alimentos conservan su procedencia americana, y después de haber pasado por una acomodación lingüística, se arraigaron en la lengua húngara y hoy se utilizan con toda naturalidad.

\section{Bibliografía}

Áldássy, Antal - Ábrányi, Kornél - Aczél, Károly - József, Ágoston (eds.). 18931900. A Pallas nagy lexikona. Az összes ismeretek enciklopédiaja. Budapest: Pallas Irodalmi és Nyomdai Részvénytársaság. Fecha de consulta: 20 de enero de 2018. Asequible en: https://adtplus.arcanum.hu/hu/view/PallasLexikon_01/?pg=4\&layout=s

Bárczi, Géza. 1932. «A “pesti nyelv”» Magyar Nyelv 28, 90. 
Benkő, Loránd (ed.) 1993. Etymologisches Wörterbuch des Ungarischen. Budapest: Akadémiai Kiadó. Fecha de consulta: 20 de enero de 2018. Asequible en: https://adtplus.arcanum.hu/hu/view/MNYTESZ_Deu/?pg=0\&layout=s

Bertalanffi, Pál. 1757. Világnak két rendbéli rövid ismerete... Nagyszombat: Az Akademiai Betőkkel.

$C O R D H=$ Banco de datos (cordh) [en línea]. Corpus diacrónico del búngaro. Fecha de consulta: 20 de enero de 2018. Asequible en: http://clara.nytud.hu/mtsz/ run.cgi/first_form

Coromines, Joan. 2011. Breve Diccionario Etimológico de la Lengua Castellana. Madrid: Gredos.

Csefkó, Gyula. 1949. “Olasz jövevényszavainkhoz” Magyar Nyelvôr, 73, 19.

Gelei, József. 1787. Ifiabbik Robinzon. Pozsony: Patzkó Ágoston Ferentz betüivel. Fecha de consulta: 20 de enero de 2018. Asequible en: http://deba.unideb.hu/ deba/magyar_museum/index.php?xf $=$ mm_1_1_10_o

Hanák, János. 1845. A természetrajz elemei. Pest: Budapesti Hiradó. Fecha de consulta: 20 de enero de 2018. Asequible en: http://clara.nytud.hu/mtsz/run.cgi/first_form

Kövecses, Zoltán. 1998. Magyar sžlengszótár. Budapest: Akadémiai Kiadó.

$M N y=$ Magyar Nyelv, revista 1905-2010. Fecha de consulta: 20 de enero de 2018. Asequible en: https://adtplus.arcanum.hu/hu/collection/MagyarNyelv/

napiszleng.hu. Fecha de consulta: 20 de enero de 2018. Asequible en: http://napiszleng.hu/romacsoki

Nyr = Magyar Nyelvór, revista 1872-2009. Fecha de consulta: 20 de enero de 2018. Asequible en: https://adtplus.arcanum.hu/hu/collection/MagyarNyelvor/

Priszter, Szaniszló. 1986. Növényneveink. Magyar-latin sqógyüjtemény. Budapest: Mezőgazdasági Kiadó.

Révay, Mór János (ed.). 1911-1935. Révai nagy lexikona. Az ismeretek enciklopédiája. Budapest: Révai Testvérek Irodalmi Intézet Részvénytársaság. Fecha de consulta: 20 de enero de 2018. Asequible en: https://adtplus.arcanum.hu/hu/ collection/RevaiLexikon/

Rózsavári, Nóra. 2017. "Chocolate, cacao y aguacate en húngaro" Erlendsdóttir, Erla-Martinell - Emma-Söhrman, Ingmar (eds.). De América a Europa. Denominaciones de alimentos americanos en lenguas europeas. Madrid: Iberoamericana-Vervuert. 359-373. 
Sánta, Ferenc. 1956. "Kakaó” Új Hang 1956/6, 14-16. Fecha de consulta: 20 de enero de 2018. Asequible en: http://clara.nytud.hu/mtsz/run.cgi/first_form Sarkadi, Imre. 1959. "A nyeremény” A sqö̈kevény 2. Budapest. Fecha de consulta: 20 de enero de 2018. Asequible en: http:/ / clara.nytud.hu/mtsz/run.cgi/first_form Surányi, Dezső. 1985. Kerti növények regénye. Budapest: Mezőgazdasági Kiadó. Szarvas, Gábor - Simonyi Zsigmond Simonyi (eds.). 1890. Magyar nyelvtörténeti sotar. Budapest: Hornyánszky Viktor akadémiai könyvkereskedése. Fecha de consulta: 20 de enero de 2018. Asequible en: https://adtplus.arcanum.hu/hu/ view/MagyarNyelvtortenetiSzotar_1/?pg=3\&layout=s

Táncsics, Mihály. 1836. Pazardi. Kolozsvár: Ref. Kollégyom betüivel. Fecha de consulta: 20 de enero de 2018. Asequible en: http://www.kiad.hu/bibl/ tancsics/index.php

Tatár, Péter. 1860. A megholt peleskei nótárius. Nagy Zajtay István másodszori feltámadása és utazása a földön. Budapest: Rózsa K. Fecha de consulta: 20 de enero de 2018. Asequible en: http://clara.nytud.hu/mtsz/run.cgi/first_form

TES z = Benkő, Loránd (ed.) 1967-1976. A magyar nyelv történeti-etimológiai szótára. Budapest: Akadémiai Kiadó. Fecha de consulta: 20 de enero de 2018. Asequible en: https://adtplus.arcanum.hu/hu/collection/MNYTESZ/

Tolcsvai Nagy, Gábor. 2007. Idegen sqavak szótára. Budapest: Osiris Kiadó.

Velich, István - Enikő V. Nagy. 1974-1983. Nálunk is megterem. Históriák és tanácsok egzotikus gyümölcs- és füszernövények nevelésébez. Budapest: Natura Könyvkiadó Vállalat. Vidor, Miklós. 1954. Szökoóár. Budapest: Kozmosz Könyvek. Fecha de consulta: 20 de enero de 2018. Asequible en: http:/ / clara.nytud.hu/mtsz/run.cgi/first_form Vörös, Éva. 1996. Egrotikus gyümölcsök magyar neveinek történeti-etimológiai szótára. Debrecen: Kossuth Egyetemi Kiadó.

Zaicz, Gábor. 2006. Etimológiai szótár. Magyar sqavak és toldalékok eredete. Budapest: Tinta Könyvkiadó. 